\title{
Evidence for crustal low shear-wave speed in western Saudi Arabia from multi-scale
} fundamental-mode Rayleigh-wave group-velocity tomography (1)

\author{
Zheng Tang ${ }^{1}$, P. Martin Mai ${ }^{1}$, Sung-Joon Chang ${ }^{2}$, and Hani Zahran ${ }^{3}$ \\ ${ }^{1}$ King Abdullah University of Science and Technology (KAUST), Thuwal, Saudi Arabia \\ ${ }^{2}$ Kangwon National University (KNU), Chuncheon, South Korea \\ ${ }^{3}$ Saudi Geological Survey (SGS), Jeddah, Saudi Arabia
}

Corresponding author: Zheng Tang, P.O. Box 4700-3770, Thuwal, Jeddah, 23955-6900, Saudi Arabia, E-mail: Zheng.Tang@kaust.edu.sa

\section{Abstract}

fundamental-mode Rayleigh-wave group-velocity tomography and shear-wave velocity inversion. The seismic dataset is compiled using $~ 140$ stations of the Saudi National Seismic Network (SNSN) operated by the Saudi Geological Survey (SGS). We measure Rayleigh-wave group-velocities at periods of 8 - $40 \mathrm{~s}$ from regional earthquakes. After obtaining 1-D shear-wave velocity models by inverting group-velocities at each grid node, we construct a 3-D shearvelocity model for Saudi Arabia and adjacent regions by interpolating the 1-D models. Our 3-D model indicates significant lateral variations in crustal and lithospheric thickness, as well as in the shear-wave velocity over the study region. In particular, we identify zones of reduced shearwave speed at crustal levels beneath the Cenozoic volcanic fields in the Arabian Shield. The 
24 inferred reductions of $2-5 \%$ in shear-wave speed may be interpreted as possibly indicating the 25 presence of partial melts. However, their precise origin we can only speculate about. Our study 26 also reveals an upper-mantle low velocity zone (LVZ) below the Arabian Shield, supporting the 27 model of lateral mantle flow from the Afar plume. Further geophysical experiments are needed 28 to confirm (or refute) the hypothesis that partial melts may exist below the Cenozoic volcanism 29 in western Saudi Arabia, and to build a comprehensive geodynamic-geological model for the evolution and present state of the lithosphere of the Arabian Plate and the Red Sea.

32 Keywords: Rayleigh-wave, group-velocity tomography, shear-velocity inversion, Arabian 33 Shield, Cenozoic volcanism

\section{Introduction}

The Arabian Plate started to separate from Africa as the Red Sea and Aden Gulf rifting began around 30 Ma ago (e.g., Camp and Roobol, 1992; Bosworth et al., 2005; Garfunkel and Beyth, 2006). It is geologically divided into two distinct terrains: the western Arabian Shield and the eastern Arabian Platform (Fig. 1). Extensive Precambrian Proterozoic basement rocks are

41 exposed in the Arabian Shield, although they underlie the entire Arabian Peninsula. Cenozoic

42 volcanic rocks, known as "harrats", mainly overlie the western part of the Arabian Shield. The

43 Arabian Platform is covered by predominant Paleozoic, Mesozoic and Cenozoic sedimentary

44 rocks with increasing thickness eastward away from the Shield (Brown, 1972; Stoeser and 45 Camp, 1985). 
The rifting of the Red Sea strongly affected the geology and recent tectonic history of

47 western Saudi Arabia. Some studies suggest that the Red Sea is passively rifting, driven by

48 extensional stresses due to far-field forces such as slab pull (e.g. Wernicke, 1985; McGuire and

49 Bohannon, 1989; Koulakov et al., 2016). Other studies (e.g. Bellahsen et al., 2003; Hansen et al.,

50 2007) argue that the Red Sea developed as an active rift, driven by hot mantle upwelling that

51 leads to thermal uplift and lithospheric thinning. In addition, the hypothesis of hybrid rifting has

52 been proposed in which the Red Sea opening is thought to be initiated passively, but is then

53 followed by a period of active processes (Camp and Roobol, 1992; Ebinger and Sleep, 1998;

54 Daradich et al., 2003). The stage of rifting is non-uniform along the Red Sea. The southern Red

55 Sea already indicates seafloor spreading and prominent volcanic activity (Ebinger and Sleep,

56 1998; Daradich et al., 2003; Xu and Jónsson, 2014), while the northern Red Sea is still at a

57 passive rifting stage (Kaban et al., 2016), and/or an active rift at the end of its continental stage

58 beginning to transit into oceanic seafloor spreading (Cochran and Martinez, 1988).

Western Arabia is dotted with areas of Cenozoic volcanism that formed during the past

$6030 \mathrm{Ma}$, showing a bimodal chemical character that indicates two distinct phases of volcanism

61 (Camp and Roobol, 1992). Older lavas (30 - $20 \mathrm{Ma})$ are tholeiitic to transitional in composition.

62 These are oriented approximately parallel to the Red Sea and have been attributed to the early

63 rifting stage of the Red Sea. In contrast, younger lavas (12 Ma to recent) are transitional to

64 alkalic, and can be found mainly along the north-south oriented Makkah-Madinah-Nafud

65 (MMN) line. Chang and Van der Lee (2011) suggests that the pronounced Cenozoic volcanism

66 originates from lateral mantle flow from the Afar and, perhaps, a hypothesized Jordan hotspot.

67 Other studies argue that a local mantle plume (Camp and Roobol, 1992) and/or a local hot 
mantle upwelling (Koulakov et al., 2016) under the Arabian Plate may play a key role in the formation of the Cenozoic lava fields.

Several geophysical studies of crustal and upper-mantle structure of the Arabian Plate

71 provide evidence for lateral variations of lithospheric properties (e.g., Mooney et al., 1985;

72 Gettings et al., 1986; Mokhtar and Al-Saeed, 1994; Sandvol et al., 1998; Rodgers et al., 1999;

73 Mokhtar et al., 2001; Kumar et al., 2002; Julià et al., 2003; Al-Damegh et al., 2005; Tkalčić et

74 al., 2006; Hansen et al., 2007; Chang and Van der Lee, 2011; Tang et al., 2016; Yao et al., 2017).

75 Generally, the crustal thickness in the Arabian Shield varies between 27 and $45 \mathrm{~km}$ (Hansen et

76 al., 2007; Tang et al., 2016), while the crustal shear-velocity ranges from 3.48 to $3.95 \mathrm{~km} / \mathrm{s}$ with

77 an average bulk Vp/Vs ratio of $1.73 \pm 0.07$ (Tang et al., 2016). Thinner crust (25 - $32.5 \mathrm{~km}$ thick)

78 with strong lateral variations is present along the Red Sea margin (Al-Damegh et al., 2005;

79 Tkalčić et al., 2006; Tang et al., 2016). The Arabian Platform has crustal shear-velocities

80 between 3.44 and $3.68 \mathrm{~km} / \mathrm{s}$ and an average bulk Vp/Vs of $1.77 \pm 0.09$ (Tang et al., 2016).

In addition, it has been inferred that the depth of the lithosphere-asthenosphere boundary

82 (LAB) varies considerably across the Arabian Peninsula, showing thin lithosphere under western

83 Arabia that thickens toward the Arabian interior (Hansen et al., 2007). Tkalčić et al. (2006)

84 observes anomalously low upper-mantle velocities and strong polarization anisotropy in the

85 lithospheric upper-mantle below the Arabian Shield. Chang and Van der Lee (2011) and Chang

86 et al. (2011) find slow shear-wave velocities at $\sim 150 \mathrm{~km}$ depth, stretching from the Afar through

87 the southern Red Sea and into the western Arabia, as well as a quasi-vertical low velocity 88 anomaly under Jordan. Yao et al. (2017) confirms the upper-mantle low velocity zone (LVZ) of $89 \sim 300 \mathrm{~km}$ width, roughly 60 - $190 \mathrm{~km}$ depths, and trending approximately north - south below the 90 MMN volcanic line. 
However, most of the above-mentioned studies are limited by poor station coverage and

92 sparse datasets. Thus, there is still considerable ambiguity regarding the lateral variations of

93 crustal and upper-mantle structure below the Arabian Shield, the regions of Cenozoic volcanism

94 (harrats), and the Arabian Platform. In this study, we aim to revise previous models by

95 conducting a fundamental-mode Rayleigh-wave group-velocity tomography and inverting for 3-

96 D shear-wave velocity structure underneath Saudi Arabia, based on a new seismic datasets

97 obtained from the Saudi Geological Survey (SGS). The new observations include seismic data

98 recorded by a dense station network (unavailable for previous studies) in the years of 2007 -

99 2014, which greatly improves the spatial coverage and helps illuminating intraplate regions. Our

100 study therefore extends previous efforts to map crustal and upper-mantle structure of Saudi

101 Arabia, and achieves higher local resolution.

In the following, we first describe the seismic data and our Rayleigh-wave group-velocity

103 measurements. The next section presents the Rayleigh-wave tomography method and resulting 104 maps of Rayleigh-wave group-velocities, followed by the description of the shear-wave velocity 105 inversion and the estimated 3-D velocity model for the entire study region. Finally, we examine 106 in detail the local velocity structure below the regions of Cenozoic volcanism in the Arabian 107 Shield and discuss possible interpretations for the observed spatial patterns of shear-wave 108 velocity variations.

\section{Seismic Data and Rayleigh-wave Group-velocity Measurements}

The Saudi Geological Survey (SGS) has operated the permanent Saudi National Seismic

113 Network (SNSN) since 2006, consisting of more than 300 stations (status December 2017). Most 
114 of the stations are equipped with either T40 or T120 Nanometrics sensors, while STS-2 115 Streckeisen instruments are operated at several sites. For our surface-wave investigation, we 116 analyze vertical component seismograms from $77 \mathrm{Mw} \geq 5.5$ regional earthquakes with an 117 epicentral distance $\leq 30^{\circ}$, recorded by the SNSN-stations in the years of $2007-2014$. Rayleigh118 wave group-velocity dispersion curves are measured by applying the multiple-filter technique 119 (MFT) of Dziewonski et al. (1969; implemented in the Computer Programs in Seismology 120 package of Herrmann and Ammon, 2002). The MFT analyzes signal amplitude as a function of 121 velocity and period, applying a Gaussian filter to isolate the wave package of interest. The width 122 of the Gaussian filter is chosen based on the epicentral distance to minimize the area of the 123 fundamental mode in the velocity-period profile surface (Ammon 2001). Before applying the 124 MFT approach, we remove the instrumental response to obtain seismograms of ground 125 displacement.

We use over 3,000 seismograms to determine Rayleigh-wave group-velocities for periods $127 \mathrm{~T}$ in the range $8 \leq \mathrm{T} \leq 40 \mathrm{~s}$. The lowest number of good quality measurements $(\sim 1,100$ rays $)$ has 128 been obtained for $\mathrm{T}=8 \mathrm{~s}$, due to the difficulty of measuring short-period group-velocities at 129 large epicentral distances. The highest number of high quality group-velocity measurements $130(\sim 3,000$ rays $)$ has been achieved for $\mathrm{T}=20 \mathrm{~s}$. Figure 2 displays the distribution of the regional 131 earthquakes used, available SNSN-stations and corresponding Rayleigh-wave ray-paths (for 132 periods $\mathrm{T}$ between 8 and 40 s) throughout Arabia. Seismic events are concentrated along plate 133 boundaries, mainly the continental/oceanic rifts (e.g., Red Sea, Gulf of Aden, Indian Ocean 134 Ridge) and the collision zones (e.g., Greece, Anatolia, Caucasus, Iran). In contrast, there are no 135 earthquake within the Arabian Plate, except the M 5.7 event located in Harrat Lunayyir that is 136 associated with the 2009 dike intrusion (Pallister et al., 2010). The spatial distribution, and hence 
137 coverage, of the 143 SNSN-stations is non-uniform, with high station density in western Saudi 138 Arabia, in particular in the volcanic regions or in zones of recently increased seismic activity.

139 Station spacing is much larger in the eastern Provinces. In general, the ray-path coverage is 140 dense within the study area, however, the coverage varies with period, and hence the final spatial 141 resolution of our inversion changes with period. Figure S1 shows the corresponding ray-density 142 maps.

To understand the spatial- and period-dependent resolution of our dataset, we group all 144 ray-paths into four clusters according to the source location for each period (Fig. 2). The first 145 cluster contains all ray-paths from northwestern directions. The second cluster includes the rays 146 from Anatolia and Caucasus in the north-northeast. The third group consists of the ray-paths 147 from the east, while the fourth group comprises the rays from the Red Sea, the Gulf of Aden and 148 the Arabian Sea in southerly directions (Fig. 2). For each cluster, the distribution of group149 velocity measurements follows a normal distribution (Fig. S2). To ensure that only high-quality 150 measurements enter the subsequent inversion, we only retain group-velocity measurements that 151 fall within three standard deviations (i.e., $99.7 \%$ of the dataset). Measurements beyond the 152 three-sigma limits are discarded.

154 3. Rayleigh-wave Group-velocity Tomography

After measuring Rayleigh-wave group-velocities at various periods, we apply the Fast 157 Marching Surface Tomography (FMST) scheme of Rawlinson (2005) to obtain Rayleigh-wave 158 group-velocity maps. The FMST is implemented iteratively in two steps: first, the fast marching 159 method (FMM) (Rawlinson and Sambridge 2005) is applied for the forward prediction step, 
160 which is then followed by a subspace inversion scheme (Kennett et al., 1988) to invert for the 161 depth-dependent S-wave structure. This last step includes the adjustment of the model 162 parameters to satisfy the observed data. The FMM is a fast and stable grid-based numerical 163 algorithm to compute the traveltime field by solving the eikonal equation with finite-difference 164 approximations (Rawlinson and Sambridge 2005). The traveltimes from sources to receivers are 165 calculated in 2-D spherical coordinates. The subspace inversion then projects the full linearized 166 inverse problem into a much smaller n-dimensional model space, thus solving the inversion only 167 for an $\mathrm{n} \times \mathrm{n}$ matrix. The FMST is therefore an iterative nonlinear method, because the repeated 168 operation of the FMM and the subspace inversion creates a nonlinear relationship between 169 seismic wave velocity and traveltime (Rawlinson and Sambridge 2005).

170 The inversion scheme can be expressed as an optimization problem. The objective 171 function is given by:

172

$173 S(m)=\left(g(m)-d_{o b s}\right) C_{d}^{-1}\left(g(m)-d_{o b s}\right)^{T}+\varepsilon\left(m-m_{0}\right) C_{m}^{-1}\left(m-m_{0}\right)^{T}+\eta m D D^{T} m^{T}$

175 where $d_{o b s}$ are the observed traveltimes, $g(m)$ are the predicted traveltimes, $m_{0}$ is the initial 176 model, $C_{d}^{-1}$ is an a priori data covariance matrix, $C_{m}^{-1}$ is an a priori model covariance matrix, $\varepsilon$ 177 is the damping parameter, $\eta$ is the smoothing factor, and $D$ is the smoothness matrix. The first 178 term on the right-hand side of Eq. 1 describes the search for a model $m$ that minimizes the misfit 179 between the predicted and observed data. The second term provides regularization to prevent the 180 solution (e.g., final model) from straying too far from the initial model. The third term constrains 181 the smoothness of the inverted model, limiting the spatial variations of model parameters 182 between neighboring nodes. 
We apply the FMST approach to the fundamental-mode Rayleigh-wave group-velocity measurements to obtain maps of group-velocity variations at periods of $8-40 \mathrm{~s}$. The study region is parameterized as a 2-D rectangular grid with a node spacing of $0.8^{\circ}$ in both latitude and longitude. We use the average group-velocities as initial values for tomographic inversion at each period. To choose the optimal damping and smoothing parameters, we investigate the tradeoff curves between root-mean-square (RMS) and model variance, as well as between RMS and model roughness obtained at periods of 10 and 30 s (Fig. S3; damping varying between 0.2 and 5; smoothing parameter between 1 and 50). The optimal damping equals to 1, while the best smoothing parameter is 4 . These values provide a good balance between model resolution and model roughness/variance. We also find that six iterations are usually sufficient to achieve convergence for the tomographic inversion.

Figure 3 shows maps of Rayleigh-wave group-velocity variations relative to the average group-velocities at periods of $8,10,15,20,25,30$, and 40 s. For reference, we also plot the characteristic shear-velocity sensitivity kernels for Rayleigh-waves at different periods. At short 197 periods (8 - 10 s) (Fig. 3a, b), group-velocity variations correlate well with surface geology. The 198 low-velocity anomalies are located in the eastern and northern Arabia, delineating the main sedimentary units including the Arabian Platform, the Persian Gulf and the Mesopotamian 200 Foredeep. Regions with thick sediments usually show much slower surface-wave group201 velocities, since sedimentary rocks have lower shear-wave velocities than crystalline crustal 202 rocks. At periods of $15-20$ s (Fig. 3c, d), the correlation between the slow group-velocities and 203 the sedimentary basins still persists. In addition, a remarkable high velocity anomaly beneath the 204 southern Red Sea appears at $15 \mathrm{~s}$ period and disappears again at period of $40 \mathrm{~s}$, indicating the 205 possible presence of oceanic crust in the southern Red Sea. Since oceanic crust is generally 
206 thinner than continental crust, the mid-period Rayleigh-waves ( $\mathrm{T}=15-20 \mathrm{~s}$, sensitive to $10-30$

$207 \mathrm{~km}$ depths) may be detecting the upper-mantle in this region. However, we note that these

208 features are at the edge of good ray coverage domain, and hence are not well resolved.

209 In addition, we detect indications of locally reduced velocity (i.e., the faint regions of dU

$210<0 \mathrm{~km} / \mathrm{s})$ below the Cenozoic volcanic fields at periods of $15-20 \mathrm{~s}$. At longer periods $(\mathrm{T}=25-$

$21140 \mathrm{~s}$; Fig. 3e-g), low group-velocities are found which are likely due to the thicker continental

212 crust under the Arabian Platform and the orogenic regions such as the Zagros Mountains. The

213 surface-wave speed at intermediate periods $(\mathrm{T}=25-40 \mathrm{~s})$ is usually slower in the regions with

214 thick crust, because crustal shear-velocities are much lower than upper-mantle shear-velocities.

215 To examine the spatial resolution of the tomographic inversion, given the available

216 dataset, we conduct a series of checkerboard tests. Such tests are needed to understand the

217 robustness and reliability of the inversion, and to assess in which region and for which period

218 geophysical interpretations are possible. Typically, the bordering zones of the study are less well

219 resolved due to fewer crossing rays, while the central part is characterized by denser ray

220 coverage (Fig. S1). However, to gain insight what exactly can be resolved in such a study,

221 checkerboard tests with changing grid spacing are conducted. Here, we construct for each period

222 an initial test model by imposing a $2.5^{\circ} \times 2.5^{\circ}$ checkerboard pattern comprising anomalies of

$223 \pm 0.8 \mathrm{~km} / \mathrm{s}$ group-velocity variations on a constant velocity background model (i.e., the

224 corresponding average group-velocity), using a bi-cubic B-spline interpolation between grid-

225 nodes. Synthetic traveltimes for the checkerboard model are computed using the FMM procedure

226 with the same ray-paths of the observed data. Finally, we obtain the recovered velocity pattern

227 using the node spacing desired in the final inversion $\left(0.8^{\circ} \times 0.8^{\circ}\right)$, applying also the same

228 regularizations. We find that the checkerboard patterns are generally well recovered (Fig. S4) for 
periods of $10-30 \mathrm{~s}$, but recovery of the checkerboard model at periods of 8 and $40 \mathrm{~s}$ is less

230 convincing due to the limited ray coverage at these two periods (Fig. 2). We also remark that the

231 periphery of our model domain is poorly resolved; correspondingly we only consider an

232 irregularly shaped central region for later interpretation. Further checkerboard tests, trying lower

233 group-velocity anomalies (e.g., $\pm 0.4 \mathrm{~km} / \mathrm{s}$ ) and/or focusing on the local region of the Cenozoic

234 volcanism, are included in the supplementary document (Fig. S5, S6).

\section{Shear-wave Velocity Inversion}

Next, we invert the Rayleigh-wave group-velocities to obtain a 1-D shear-wave velocitydepth profile at each grid node, following the approach of Herrmann and Ammon (2002). These profiles are then combined to generate a 3-D shear-velocity model of the Earth crust and uppermantle below Saudi Arabia. Group-velocities between period 8 and $40 \mathrm{~s}$ are extracted from our tomography results, while we rely on group-velocity measurements of Ma and Masters (2014) at

243 longer periods $(T=40-133$ s) to constrain the lithospheric mantle. Ma and Masters (2014) 244 obtained millions of high-quality fundamental-mode Rayleigh- and Love-wave group-velocity 245 measurements at periods $\mathrm{T}=25-133 \mathrm{~s}$ (utilizing a cluster analysis technique), and reported the 246 global lateral variations of group-velocity. Their cluster approach measures surface-wave 247 velocities for all recordings from a single event at a single target period, instead of making 248 measurements for all periods for a single event-station pair (Ma and Masters, 2014). Although 249 their tomographic results are based on a block size of $1^{\circ}$ by $1^{\circ}$, the best resolution is around $5^{\circ}$ 250 (50 s period Rayleigh-wave, according to their checkerboard tests). Despite the nominal lower 
resolution of the Ma and Masters dataset, we consider it important for our study in order to help constrain the deeper (below $\sim 50 \mathrm{~km}$ depth) Earth structure underneath Saudi Arabia.

We parameterize our starting model as a stack of layers with constant thickness and 254 constant velocity. Layer thicknesses are $5 \mathrm{~km}$ in the Earth crust and uppermost mantle $(0-60$ $255 \mathrm{~km})$, and then progressively increase to $10 \mathrm{~km}$ in the lithospheric mantle levels $(60-120 \mathrm{~km})$ and 256 to $20 \mathrm{~km}$ at deeper depths. In our previous study (Tang et al., 2016), we constructed 1-D shear257 wave velocity-depth profiles of crust and uppermost mantle at 56 SNSN-stations by jointly 258 inverting P-wave receiver functions and surface-wave dispersion data. Correspondingly, we use 259 the average shear-velocity model from these 56 SNSN-stations as the starting model for the 260 depth range of $0-50 \mathrm{~km}$, with P-velocity and density for each layer being based on the joint 261 inversion models of Tang et al. (2016). At larger depths (50 - $220 \mathrm{~km})$, we choose the global 1-D 262 model AK135 as starting model. For the 1-D shear-velocity inversion at each grid node, 263 differential smoothing is applied to damp the differences between the shear-wave velocity 264 perturbations in adjacent layers (Herrmann and Ammon, 2002). The function to be minimized in 265 the inversion can be expressed as MIN $=|\delta y-\mathbf{A} \cdot \delta x|+|\theta \mathbf{D} \cdot \delta x|$, where vector $\delta x$ represents 266 shear-velocity model perturbations, $\delta y$ is the data residual, matrix A contains the sensitivity 267 kernel, vector D $\cdot \delta x$ contains the first differences between shear-velocity perturbations in 268 adjacent layers, and $\theta$ is the damping factor that we set equal to 1.

269 Figure 4 illustrates the 1-D shear-velocity inversion procedure at two nodes. One node 270 (Fig 4a) is located on the Arabian Shield (lat. 24.2 $2^{\circ}$, long. 40.0 $0^{\circ}$, showing a $\sim 35 \mathrm{~km}$ thick crust, 271 a very thin upper-mantle lid, and slow velocities in the upper-mantle. In contrast, the other site 272 (Fig 4b) is on the Arabian Platform (lat. 27.4 , long. 48.8 ${ }^{\circ}$, displaying thick sediments $(\sim 10$ $273 \mathrm{~km}$ ), crust and lithosphere. Note that the observed Rayleigh-wave group-velocity dispersion 
274 curve (triangles in Fig. 4) is a combination of group-velocities at 8 - $40 \mathrm{~s}$ periods from our 275 tomography, as well as the group-velocities at periods of 40 - $133 \mathrm{~s}$ from Ma and Masters (2014) 276 within our study region. The starting model is a combination of the average 1-D model for 0 - 50 $277 \mathrm{~km}$ depths from Tang et al. (2016), and the AK135 model for 50 - $220 \mathrm{~km}$ depths. Additionally, 278 A few further tests and comparisons, such as applying a different starting model (e.g., AK135 279 model), comparing with the previous results from joint inversion (Tang et al. 2016), are included 280 in the e-supplement (Fig. S7 - S10).

281 To assess the spatial resolution of our 3-D model, we perform checkerboard tests with 282 various grid parameterizations. The initial test model of variable input S-wave velocities follows 283 a $2.5^{\circ} \times 2.5^{\circ}$ checkerboard pattern with $\pm 0.4 \mathrm{~km} / \mathrm{s}$ (i.e., $\pm 10 \%$ ) S-wave anomalies in horizontal 284 sections. In vertical direction, the signs change at depths of $5 \mathrm{~km}, 20 \mathrm{~km}, 40 \mathrm{~km}$, and $70 \mathrm{~km}$. The 285 first step when creating the synthetic data is to compute 2-D maps of Rayleigh-wave group286 velocities for all periods (i.e., 8 - 40 s). For each grid node within the study area, we then 287 calculate expected group-velocities based on the 1-D model corresponding to that node. 288 Subsequently, we compute the synthetic Rayleigh-wave travel times and apparent group289 velocities for all included ray-paths (i.e., event - station pairs) in the original dataset at each 290 period. We then treat the synthetic Rayleigh-wave travel times and apparent group-velocities as 291 "real" data that we then use to perform the surface wave tomography. From the corresponding 2292 D maps of group-velocities, we then invert for the shear-velocity model, following the same 293 procedures described in section 3 and 4. Figure 5 shows the result of the synthetic test for the 294 entire study region. The three horizontal slices show that the checkerboard anomalies are well 295 recovered in the central part of our study domain, but resolution degrades at the boundaries. In 296 the southwest, this boundary roughly coincides with the Red Sea coastline. In the vertical 
sections, four layers with different signs of anomalies are well restored, indicating excellent resolution within the upper $\sim 80 \mathrm{~km}$ depth. These tests show the robustness of our inversion results, and provide important information for further geophysical, geological, geodynamic interpretation.

Finally, we obtain a set of 1-D inverted models that we interpolate to construct a 3-D shear-wave velocity model for Saudi Arabia. Figure 6 displays a set of horizontal depth-slices of shear-wave velocity perturbations (in \%) from our 3-D shear-wave velocity model at crustal levels. At 0 - $10 \mathrm{~km}$ depths (Fig. 6a, b), the S-wave velocity patterns clearly reflect our Rayleighwave group-velocity patterns at 8 - 10 s periods (Fig $3 \mathrm{a}, \mathrm{b}$ ), in which slower velocities correlate well with the presence of sedimentary basins, including the Arabian Platform, the Persian Gulf and the Mesopotamian Foredeep. We also detect low velocity zones beneath the Cenozoic volcanic regions (i.e., harrats) at 10 - $30 \mathrm{~km}$ depths (Fig. 6c-f), with S-wave velocity reductions of $2-3 \%$ with respect to the corresponding reference wave speeds. Even at $25-30 \mathrm{~km}$ depths (Fig. 6f), most areas, including the Platform and the eastern Shield, show crustal shear-velocities

311 that are comparatively slow, while the Red Sea margin indicates relatively high velocities 312 corresponding to S-wave speeds expected at the lower-crustal levels and near the Moho. In 313 summary, we detect thinner crust along the Arabian margin of the Red Sea, which has been 314 hinted in previous studies (Al-Damegh et al., 2005; Tkalčić et al., 2006; Tang et al., 2016). At 30 $315-35 \mathrm{~km}$ depths (Fig. 6g), most regions of the Arabian Shield have reached the lower crust and 316 even Moho discontinuity. However, both the southern Arabian Shield and the Arabian Platform 317 are still showing crustal velocities $(\sim 3.7-3.9 \mathrm{~km} / \mathrm{s})$. At $35-45 \mathrm{~km}$ depths (Fig. $6 \mathrm{~h}, \mathrm{i})$, we find 318 that S-wave speeds underneath the Arabian Shield has reached values expected at the Moho and 319 the uppermost mantle. In contrast, the southern Arabian Shield and the Arabian Platform reveal 
320 still lower-crustal velocities. Our high-resolution study therefore clearly demonstrates that the 321 southern Arabian Shield and the Arabian Platform have thicker crust ( $\geq 45 \mathrm{~km})$ than the western 322 part of the Arabian Shield ( $\sim 35-40 \mathrm{~km})$, corroborating previous results (Tang et al., 2016).

323 Figure 7 displays horizontal depth-slices of S-wave velocity anomalies for upper-mantle 324 depth levels. We find a substantial low S-wave velocity anomaly underneath the southwestern 325 part of our study region, near the Red Sea coastline (Fig. 7, b-1), continuing from $\sim 50 \mathrm{~km}$ to 326 perhaps over $180 \mathrm{~km}$ depths. This may be related to findings by Chang and Van der Lee (2011). 327 They mapped slow S-wave velocities within the upper-mantle below the southern Red Sea. This 328 domain of low S-wave velocities implies that the lithospheric thickness is no more than $50 \mathrm{~km}$ 329 beneath the southern Red Sea and the nearby coastal regions, consistent with previous local LAB 330 estimations (Hansen et al., 2007).

In addition, we identify isolated low S-wave velocity anomalies beneath the areas of 332 Cenozoic volcanism in the Arabian Shield, extending over the depth range $55-70 \mathrm{~km}$ (Fig. 7c, 333 d). As depth increases, these low velocity anomalies expand into interconnected low shear334 velocity zones (LVZ), including the Arabian Shield and even northern Arabia (beneath Jordan 335 and Syria, however, the resolution of our model is limited in this region). Our results thus 336 corroborate and extend previous findings regarding the LVZ that have been proposed, being a 337 northward extension from the Afar plume (Chang and Van der Lee, 2011; Chang et al., 2011; 338 Yao et al., 2017). Our velocity maps also indicate thin lithosphere ( 60 - $90 \mathrm{~km}$ thick) and 339 slower upper-mantle S-wave velocities in the Arabian Shield, compared to thicker lithosphere 340 and relatively high upper-mantle velocities of the Arabian Platform. However, our 3-D inversion 341 model cannot reveal further details of this LVZ, because the upper-mantle structure is largely 
342

343

344

\section{5}

346

347

348

349

350

351

352

353

354

355

356

357

.

constrained by the large-scale group-velocity tomography of Ma and Masters (2014) whose resolution is spatially limited.

\section{Discussion and Implications}

The most intriguing features in our 3-D model are the zones of low S-wave velocity at crustal levels underneath the regions of Cenozoic volcanism, and the upper-mantle LVZ below the Arabian Shield. In the following, we discuss possible explanations for the presence of these S-wave velocity anomalies as well as implications for understanding the Cenozoic volcanism of western Arabia.

\subsection{S-wave anomalies underneath the Cenozoic Volcanism}

Our inversion documents the presence of low S-wave velocity anomalies at $10-30 \mathrm{~km}$ depths below the Cenozoic volcanic areas (Fig. 6c-f) of Saudi Arabia. To further examine the details of these low-velocity features, we zoom into the regions of Cenozoic volcanism in the Arabian Shield to obtain images of higher spatial resolution. For this purpose, we follow the same procedure as before, conducting Rayleigh-wave group-velocity tomography followed by shear-wave velocity inversion with all available rays and stations, but now focusing on the local harrats. Because the spacing of the SNSN-stations is much denser over the region of Cenozoic volcanism, hence better ray coverage is achieved that allows a closer node spacing of $0.5^{\circ}$ in both latitude and longitude (instead of $0.8^{\circ}$ as previously). Furthermore, we experiment with the needed regularizations for the Rayleigh-wave tomography, and find optimal smoothing $(\eta=2)$ 
and damping parameter $(\varepsilon=1)$ for obtaining higher resolution velocity maps. As a result, we are able to generate a refined 3-D shear-wave velocity model for the area of Cenozoic volcanism. As

367 before, we carry out checkerboard tests for this local region (Fig. 8) to assess the robustness and 368 reliability of our inversion. The horizontal resolution for the local 3-D model is about $1.5^{\circ} \times$ $3691.5^{\circ}$, which is substantially better than that for the entire study area. Correspondingly, the depth370 dependent velocity anomalies under the volcanic areas are well resolved (Fig. 8).

372 slices (Fig. 9) and three vertical sections (Fig. 10). The local 3-D model reveals low shear-wave 373 velocity anomalies beneath the Cenozoic volcanic fields at crustal levels. These include the low 374 velocity zone at $\sim 10-25 \mathrm{~km}$ depths near Harrat Rahat and Harrat Khaybar, the low velocities at $375 \sim 10$ - $35 \mathrm{~km}$ depths extending from Harrat Khaybar, to Harrat Lunayyir and Harrat Uwayrid, and 376 the low velocity feature at $\sim 10-35 \mathrm{~km}$ depths directly below Harrat Nawasif, Harrat Hadan and 377 Harrat Kishb. The reduction in shear-wave speed appear largest in the later area, reaching 5\%, 378 while overall it is on the order of $2-3 \%$ in lower-crustal depths $(15-35 \mathrm{~km})$. We also detect a 379 low velocity anomaly at roughly $25-50 \mathrm{~km}$ depths in the northeastern corner of the study 380 domain, perhaps related to Harrat Hutaymah. The vertical transects (Fig. 10) provide further 381 details on the depth extent and lateral variations of the low velocity features below the harrats.

382 Interpreting in detail these regions of reduced shear-wave speed is not straightforward, as 383 additional geophysical and geological information (temperature gradient, attenuation, anisotropy, 384 conductivity, mineralogy) are missing in order to decipher the rock composition and potential 385 presence of partial melts. Naturally, the zones of low S-wave speed underneath Cenozoic 386 volcanic fields lend themselves to be interpreted as regions of partial melts that somehow feed 
the surface volcanism. However, let us first discuss the spatial pattern of the observed low Swave velocities before we speculate about their nature.

Figure 10 shows that the zone of low S-wave speed within the upper-mantle connects to the crustal low velocity zones in the region of Harrat Khaybar, northern Harrat Rahat, and Harrat Uwayrid. This suggests a possible "conduit" (between $\sim 40-70 \mathrm{~km}$ depths, at lat. $\sim 26^{\circ}$ and long. $\sim 39.5^{\circ}$ ) through which magma may ascend from the upper mantle levels into the crust. This “conduit" appears to bifurcate into several branches (Fig. 10, cross-section C-C'). One branch

394 ascends toward the southeast, arriving below Harrat Khaybar and northern Harrat Rahat. Another 395 branch rises toward the northwest, reaching Harrat Uwayrid. The third one rises toward the west, arriving beneath Harrat Lunayyir, while another one appears to stretch towards the east at depths

397 of around $20 \mathrm{~km}$. Our findings therefore suggest the possible existence of a complex network of 398 potential magma conduits that may feed the Cenozoic surface volcanism in Saudi Arabia. Notice 399 also the regions of low S-wave speed beneath Harrat Nawasif, Harrat Hadan, and Harrat Kishb 400 are disconnected from the upper-mantle LVZ, while the S-wave anomalies under Harrat 401 Khaybar, northern Harrat Rahat, and Harrat Uwayrid are connected to the upper-mantle LVZ. It 402 is interesting to note that the age of surface lavas in the harrats decreases from south to north 403 (roughly coinciding with profile C-C' in Fig. 10) (Camp and Roobol, 1992), thus, the S-wave 404 anomalies under the southern harrats (with older lavas) appear as currently isolated features in 405 the crust. Further support for our results are provided by Koulakov et al. (2015) who map lower 406 S-velocities, higher P-velocities and increased Vp/Vs ratios at $\sim 7-15 \mathrm{~km}$ depths under Harrat 407 Lunayyir, which they interpret as a steady-state magma reservoir. They also suggest the presence 408 of a conduit below $\sim 15 \mathrm{~km}$ depth for fluids and melts from deeper sources. 
Figure 10 reveals a spatial correlation of the S-wave anomalies with the Cenozoic surface

413 volcanism, however, correlation does not mean causality. Yet, the inferred localized reductions

414 in shear-wave speed of $2-3 \%$ (locally even $5 \%$ ) that we observe underneath the harrats may be

415 related to the origin of the volcanism. Since further geophysical information for these depths (15

$416-35 \mathrm{~km}$ ) in terms of conductivity, attenuation, or anisotropy are absent that are needed to

417 determine the physical in-situ rock properties, we can only hypothesize what these velocity 418 reductions represent. Following Hacker et al (2014) and their approach on estimating the effect

419 of melt on shear-wave speed based on Schmeling (1985), we find that $3 \%$ S-wave speed 420 reductions can be explained by $1.5-3.5 \%$ partial melt, depending on melt geometry. For $2 \% \mathrm{~S}-$ 421 wave velocity reduction, this percentage of partial melt reduces to $1.0-2.5 \%$; for a $-5 \%$ shear422 wave-speed anomaly, $2.5-5.0 \%$ partial melt is expected. As we lack more detailed geological 423 and geophysical information, we speculate that the imaged shear-wave velocity reductions of $424 \sim 3 \%$ are due to $\sim 2 \%$ partial melts that are localized in relatively broad anomalies of $50-100$ $425 \mathrm{~km}$ horizontal and $10-15 \mathrm{~km}$ vertical extend (Fig. 10). Notice that $2 \%$ of partial melt is 426 considered a small amount, which however is sufficient to significantly reduce the S-wave speed 427 (Hacker et al, 2014).

428 If indeed present, how are these small amount of partial melts generated? Our images of 429 the upper-mantle LVZ across the Arabian Shield and even into Jordan may provide some clues. 430 Associated with the approximately north - south orientation of the fast axis from shear-wave 431 splitting measurements (Gashawbeza et al., 2004; Hansen et al., 2006; Elsheikh et al., 2014), our 432 results are consistent with the model of lateral mantle flow from the Afar hotspot (Chang and 
433 Van der Lee, 2011; Chang et al., 2011). However, the relation between the laterally-transported 434 plume material and the surface volcanism in the western Arabia remains ambiguous. If large 435 amounts of migrated Afar plume material is heating (even "flooding") the bottom of the Arabian 436 Shield's lithosphere (Ebinger and Sleep, 1998; Chang and Van der Lee, 2011; Chang et al., 437 2011), local lithospheric melts and mixed plume material should feed the Cenozoic volcanism. 438 However, geochemical analyses (Bertrand et al., 2003) on basalts report that the magmas for the 439 volcanism in Saudi Arabia, Jordan and Syria do not originate from Afar mantle-plume material, 440 but rather from Arabian lithospheric mantle. Also, the western Arabian lavas are not affected by 441 crustal contamination (Bertrand et al., 2003), although some possible contaminants residing in 442 both upper and lower crust have been identified in some basalts from Yemen (Baker et al., 1996; 443 Baker et al., 1997). In addition, Konrad et al. (2016) reports that only lavas found at Harrat Rahat 444 (directly above the MMN line) show a "weak but detectable plume signal", suggesting only a 445 small quantity of entrained plume material, whereas the dominant magma source for all the other 446 harrats appears to be the Proterozoic lithospheric mantle. Therefore, it seems likely that only a 447 small amount of plume material from Afar has arrived at the southern tip (i.e., Harrat Rahat) of 448 the MMN volcanic line. The typical mantle convection speed near the crust is $\sim 20 \mathrm{~mm} / \mathrm{yr}$ (Liu et 449 al., 2007). Assuming a similar velocity for the lateral northwards mantle flow from the Afar, the 450 distance traveled for the laterally-transported Afar plume material is $\sim 600 \mathrm{~km}$ since the onset of 451 Cenozoic volcanism (i.e., 30 Ma). Obviously, this distance is insufficient to cover the Arabian 452 Shield.

453 Correspondingly, the hypothesized fraction of partial melt is likely produced locally, at 454 least to a large extent. Partial melting may occur in form of decompression melting, in the 455 present case triggered by lithospheric thinning associated with the Red Sea rifting. Additional 
456 heating due to lateral mantle flow from the Afar hotspot may further contribute to the 457 lithospheric melting under the southern Arabian Shield.

However, to map further details of the inferred low shear-wave speed anomalies and to understand their rock-physical properties and geodynamic origin, further geophysical investigations, associated with geochemical and geological studies, are needed. These will also

461 help to address the question whether there is a lithospheric-to-crustal "plumbing system" 462 underneath the Arabian Shield that feeds the Cenozoic volcanism, or whether the well-resolved

463 low shear-velocity anomalies present deep-seated isolated reservoirs of partial melts that are occasionally fed by lithospheric melts mixed with local asthenospheric mantle material.

\section{Conclusions}

We conduct a fundamental-mode Rayleigh-wave group-velocity tomography and develop

470 regions using the regional seismic data. Through a series of checkerboard tests, we establish the 471 limits of resolution of our dataset, and thus document good spatial resolution over most parts of 472 the study region. Our results greatly improve previous models of crust-and-mantle structure 473 underneath Saudi Arabia, and help investigating the underlying geodynamical processes in this 474 area. In particular, we identify low shear-wave velocity anomalies at crustal levels in regions of 475 Cenozoic surface volcanism, which we interpret as areas that comprise $\sim 2 \%$ partial melt. We 476 also image the upper-mantle LVZ below the western Arabia, supporting a previous model of 477 lateral mantle migration from the Afar hotspot (Chang et al., 2011). We speculate that only a 478 small amount of plume material from the Afar has arrived at the southern tip (i.e., Harrat Rahat) 
479 of the Cenozoic volcanism area. The generation of local lithospheric mantle melts under the

480 Arabian Shield may be caused by decompression partial melting associated with lithospheric 481 thinning during the Red Sea opening. In this case, lithospheric melts, mixed with local 482 asthenospheric material, may provide the main magma source of the late-Cenozoic volcanism in 483 the western Arabia.

\section{Acknowledgements} for Earthquakes and Volcanoes (NCEV) at the Saudi Geological Survey (SGS) for providing the 489 broadband seismic data. We also thank Mohammed Soliman and two anonymous reviewers for their constructive comments that help greatly to improve the manuscript. We acknowledge 491 support by Kangwon National University (KNU) for hosting Z.T. during a research collaboration 492 visit in September 2015. The research presented in this paper was supported by funding from 493 King Abdullah University of Science and Technology (KAUST), grant number BAS/1/1339-01494 01. S.-J.C was supported by the Korea Meteorological Administration Research and 495 Development Program under grant KMIPA 2015-7030.

\section{References}

499 Al-Damegh, K., Sandvol, E., \& Barazangi, M. (2005). Crustal structure of the Arabian plate: new constraints from the analysis of teleseismic receiver functions. Earth and Planetary Science Letters, 231(3), 177-196. 
502 Ammon, C. J. Notes on Seismic Surface-Wave Processing, Part I, Group Velocity 503 Estimation.(2001). Saint Louis University. Version, 3(0).

504 Baker, J. A., Thirlwall, M. F., \& Menzies, M. A. (1996). Sr Nd Pb isotopic and trace element 505 evidence for crustal contamination of plume-derived flood basalts: Oligocene flood volcanism in western Yemen. Geochimica et Cosmochimica Acta, 60(14), 2559-2581.

507 Baker, J. A., Menzies, M. A., Thirlwall, M. F., \& Macpherson, C. G. (1997). Petrogenesis of 508 Quaternary intraplate volcanism, Sana'a, Yemen: implications for plume-lithosphere 509 interaction and polybaric melt hybridization. Journal of Petrology, 38(10), 1359-1390.

510 Bellahsen, N., Faccenna, C., Funiciello, F., Daniel, J. M., \& Jolivet, L. (2003). Why did Arabia separate from Africa? Insights from 3-D laboratory experiments. Earth and Planetary Science Letters, 216(3), 365-381.

513 Bertrand, H., Chazot, G., Blichert-Toft, J., \& Thoral, S. (2003). Implications of widespread 514 high- $\mu$ volcanism on the Arabian Plate for Afar mantle plume and lithosphere 515 composition. Chemical Geology, 198(1), 47-61.

516 Bosworth, W., Huchon, P., \& McClay, K. (2005). The red sea and gulf of Aden basins. Journal 517 of African Earth Sciences, 43(1), 334-378.

518 Brown, G. F. (1972). Tectonic map of the Arabian Peninsula (No. 72-52). US Geological 519 Survey.

520 Camp, V. E., \& Roobol, M. J. (1992). Upwelling asthenosphere beneath western Arabia and its 521 regional implications. Journal of Geophysical Research, 97(B11), 15255-15271.

522 Chang, S. J., Merino, M., Van der Lee, S., Stein, S., \& Stein, C. A. (2011). Mantle flow beneath Arabia offset from the opening Red Sea. Geophysical Research Letters, 38(4). 
Chang, S. J., \& Van der Lee, S. (2011). Mantle plumes and associated flow beneath Arabia and East Africa. Earth and Planetary Science Letters, 302(3), 448-454.

Cochran, J. R., \& Martinez, F. (1988). Evidence from the northern Red Sea on the transition from continental to oceanic rifting. Tectonophysics, 153(1-4), 25-53.

Daradich, A., Mitrovica, J. X., Pysklywec, R. N., Willett, S. D., \& Forte, A. M. (2003). Mantle flow, dynamic topography, and rift-flank uplift of Arabia. Geology, 31(10), 901-904.

Dziewonski, A., Bloch, S., \& Landisman, M. (1969). A technique for the analysis of transient seismic signals. Bulletin of the seismological Society of America, 59(1), 427-444.

Ebinger, C. J., \& Sleep, N. H. (1998). Cenozoic magmatism throughout east Africa resulting from impact of a single plume. Nature, 395(6704), 788-791.

Elsheikh, A. A., Gao, S. S., Liu, K. H., Mohamed, A. A., Yu, Y., \& Fat-Helbary, R. E. (2014). Seismic anisotropy and subduction-induced mantle fabrics beneath the Arabian and Nubian Plates adjacent to the Red Sea. Geophysical Research Letters, 41(7), 2376-2381.

Garfunkel, Z., \& Beyth, M. (2006). Constraints on the structural development of Afar imposed by the kinematics of the major surrounding plates. Geological Society, London, Special Publications, 259(1), 23-42.

Gashawbeza, E. M., Klemperer, S. L., Nyblade, A. A., Walker, K. T., \& Keranen, K. M. (2004). Shear-wave splitting in Ethiopia: Precambrian mantle anisotropy locally modified by Neogene rifting. Geophysical Research Letters, 31(18).

Gettings, M. E., Blank, H. R., Mooney, W. D., \& Healey, J. H. (1986). Crustal structure of southwestern Saudi Arabia. Journal of Geophysical Research: Solid Earth (1978-2012), 91(B6), 6491-6512. 
546 Hacker, B. R., M. H. Ritzwoller, and J. Xie (2014), Partially melted, micabearing crust in Central Tibet, Tectonics, 33, 1408-1424, doi:10.1002/ 2014TC003545.

548 Hansen, S. E., Rodgers, A. J., Schwartz, S. Y., \& Al-Amri, A. M. (2007). Imaging ruptured 549 lithosphere beneath the Red Sea and Arabian Peninsula. Earth and Planetary Science Letters, 259(3), 256-265.

Hansen, S., Schwartz, S., Al-Amri, A., \& Rodgers, A. (2006). Combined plate motion and 552 density-driven flow in the asthenosphere beneath Saudi Arabia: Evidence from shearwave splitting and seismic anisotropy. Geology, 34(10), 869-872.

554 Herrmann, R., \& Ammon, C. (2002). Computer Programs in Seismology, version 3.30, Saint Louis University, St. Louis, Missouri.

556 Julià, J., Ammon, C. J., \& Herrmann, R. B. (2003). Lithospheric structure of the Arabian Shield 557 from the joint inversion of receiver functions and surface-wave group velocities. Tectonophysics, 371(1), 1-21.

559 Kaban, M. K., El Khrepy, S., Al-Arifi, N., Tesauro, M., \& Stolk, W. (2016). Three-dimensional 560 density model of the upper mantle in the Middle East: Interaction of diverse tectonic 561 processes. Journal of Geophysical Research: Solid Earth, 121(7), 5349-5364.

562 Kennett, B. L. N., Sambridge, M. S., \& Williamson, P. R. (1988). Subspace methods for large 563 inverse problems with multiple parameter classes. Geophysical Journal International,

565 Konrad, K., Graham, D. W., Thornber, C. R., Duncan, R. A., Kent, A. J., \& Al-Amri, A. M. 566 (2016). Asthenosphere-lithosphere interactions in Western Saudi Arabia: Inferences from $3 \mathrm{He} / 4 \mathrm{He}$ in xenoliths and lava flows from Harrat Hutaymah. Lithos, 248, 339-352. 
568 Koulakov, I., Burov, E., Cloetingh, S., El Khrepy, S., Al-Arifi, N., \& Bushenkova, N. (2016). Evidence for anomalous mantle upwelling beneath the Arabian Platform from travel time tomography inversion. Tectonophysics, 667, 176-188.

571 Koulakov, I., El Khrepy, S., Al-Arifi, N., Kuznetsov, P., \& Kasatkina, E. (2015). Structural 572 cause of a missed eruption in the Harrat Lunayyir basaltic field (Saudi Arabia) in 2009. $573 \quad$ Geology, 43(5), 395-398.

574 Kumar, M. R., Ramesh, D. S., Saul, J., Sarkar, D., \& Kind, R. (2002). Crustal structure and 575 upper mantle stratigraphy of the Arabian shield. Geophysical Research Letters, 29(8), 576 $130-1$.

577 Liu, J., Liu, Q. Y., Guo, B., Yuen, D. A., \& Song, H. Z. (2007). Small-scale convection in the 578 upper mantle beneath the Chinese Tian Shan Mountains. Physics of the Earth and 579 Planetary Interiors, 163(1), 179-190.

580 Ma, Z., \& Masters, G. (2014). A new global Rayleigh-and Love-wave group velocity dataset for 581 constraining lithosphere properties. Bulletin of the Seismological Society of America, $582 \quad 104(4), 2007-2026$.

583 McGuire, A. V., \& Bohannon, R. G. (1989). Timing of mantle upwelling: evidence for a 584 passive origin for the Red Sea rift. Journal of Geophysical Research: Solid Earth, 94(B2), 585 $1677-1682$.

586 Mokhtar, T. A., \& Al-Saeed, M. M. (1994). Shear wave velocity structures of the Arabian 587 Peninsula. Tectonophysics, 230(1), 105-125.

588 Mokhtar, T. A., Ammon, C. J., Herrmann, R. B., \& Ghalib, H. A. A. (2001). Surface wave 589 velocities across Arabia. PAGEOPH 158, No. 8, pp. 1425-1444. 
590

591

592

593

594

595

596

597

598

599

600

601

602

603

604

605

606

607

608

609

610

611

Mooney, W. D., Gettings, M. E., Blank, H. R., \& Healy, J. H. (1985). Saudi Arabian seismicrefraction profile: a traveltime interpretation of crustal and upper mantle structure. Tectonophysics, 111(3), 173-246.

Pallister, J. S., McCausland, W. A., Jónsson, S., Lu, Z., Zahran, H. M., El Hadidy, S., ... \& Moufti, M. R. (2010). Broad accommodation of rift-related extension recorded by dyke intrusion in Saudi Arabia. Nature Geoscience, 3(10), 705-712.

Rawlinson, N. (2005). FMST: Fast Marching Surface Tomography package-Instructions. Research School of Earth Sciences, Australian National University, Canberra.

Rawlinson, N., \& Sambridge, M. (2005). The fast marching method: an effective tool for tomographic imaging and tracking multiple phases in complex layered media. Exploration Geophysics, 36(4), 341-350.

Rodgers, A. J., Walter, W. R., Mellors, R. J., Al-Amri, A. M., \& Zhang, Y. S. (1999). Lithospheric structure of the Arabian Shield and Platform from complete regional waveform modelling and surface wave group velocities. Geophysical Journal International, 138(3), 871-878.

Sandvol, E., Seber, D., Calvert, A., \& Barazangi, M. (1998). Grid search modeling of receiver functions: Implications for crustal structure in the Middle East and North Africa. Journal of Geophysical Research: Solid Earth (1978-2012), 103(B11), 26899-26917.

Schmeling, H. (1985), Numerical models on the influence of partial melt on elastic, anelastic and electric properties of rocks, Part I: Elasticity and anelasticity, Phys. Earth Planet. Inter., 41, 34-57.

Stoeser, D. B., \& Camp, V. E. (1985). Pan-African microplate accretion of the Arabian Shield. Geological Society of America Bulletin, 96(7), 817-826. 
613 Tang, Z., Julià, J., Zahran, H., \& Mai, P. M. (2016). The lithospheric shear-wave velocity 614 structure of Saudi Arabia: Young volcanism in an old shield. Tectonophysics, 680, 8-27.

615 Tkalčić, H., Pasyanos, M. E., Rodgers, A. J., Gök, R., Walter, W. R., \& Al-Amri, A. (2006). A 616 multistep approach for joint modeling of surface wave dispersion and teleseismic receiver 617 functions: Implications for lithospheric structure of the Arabian Peninsula. Journal of 618 Geophysical Research: Solid Earth (1978-2012), 111(B11).

619 Wernicke, B. (1985). Uniform-sense normal simple shear of the continental lithosphere. 620 Canadian Journal of Earth Sciences, 22(1), 108-125.

621 Xu, W., \& Jónsson, S. (2014). The 2007-8 volcanic eruption on Jebel at Tair island (Red Sea) 622 observed by satellite radar and optical images. Bulletin of Volcanology, 76(2), 1-14.

623 Yao, Z., Mooney, W. D., Zahran, H. M., \& Youssef, S. E. H. (2017). Upper mantle velocity 624 structure beneath the Arabian Shield from Rayleigh surface wave tomography and its 625 implications. Journal of Geophysical Research: Solid Earth.

626 


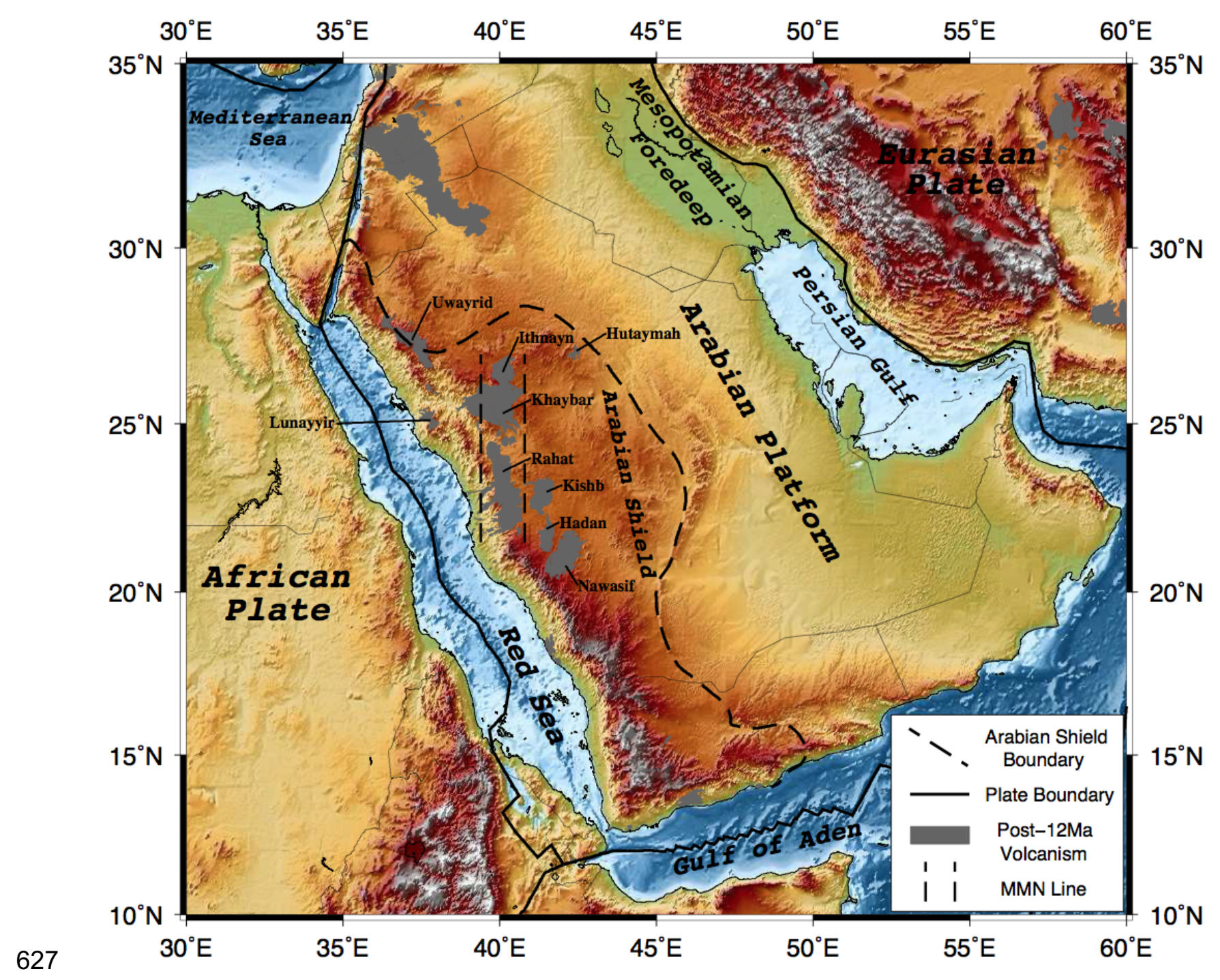

628 Figure 1. Geographic map of the Arabian Plate and its surrounding regions, showing the main

629 geologic features, the Cenozoic volcanism during the past $12 \mathrm{Ma}$ (gray-shaded regions), and the

630 so-called Makkah-Madinah-Nafud (MMN) volcanic line. Main volcanic regions (called harrats

631 locally) are indicated by their names to which we refer in the text. 


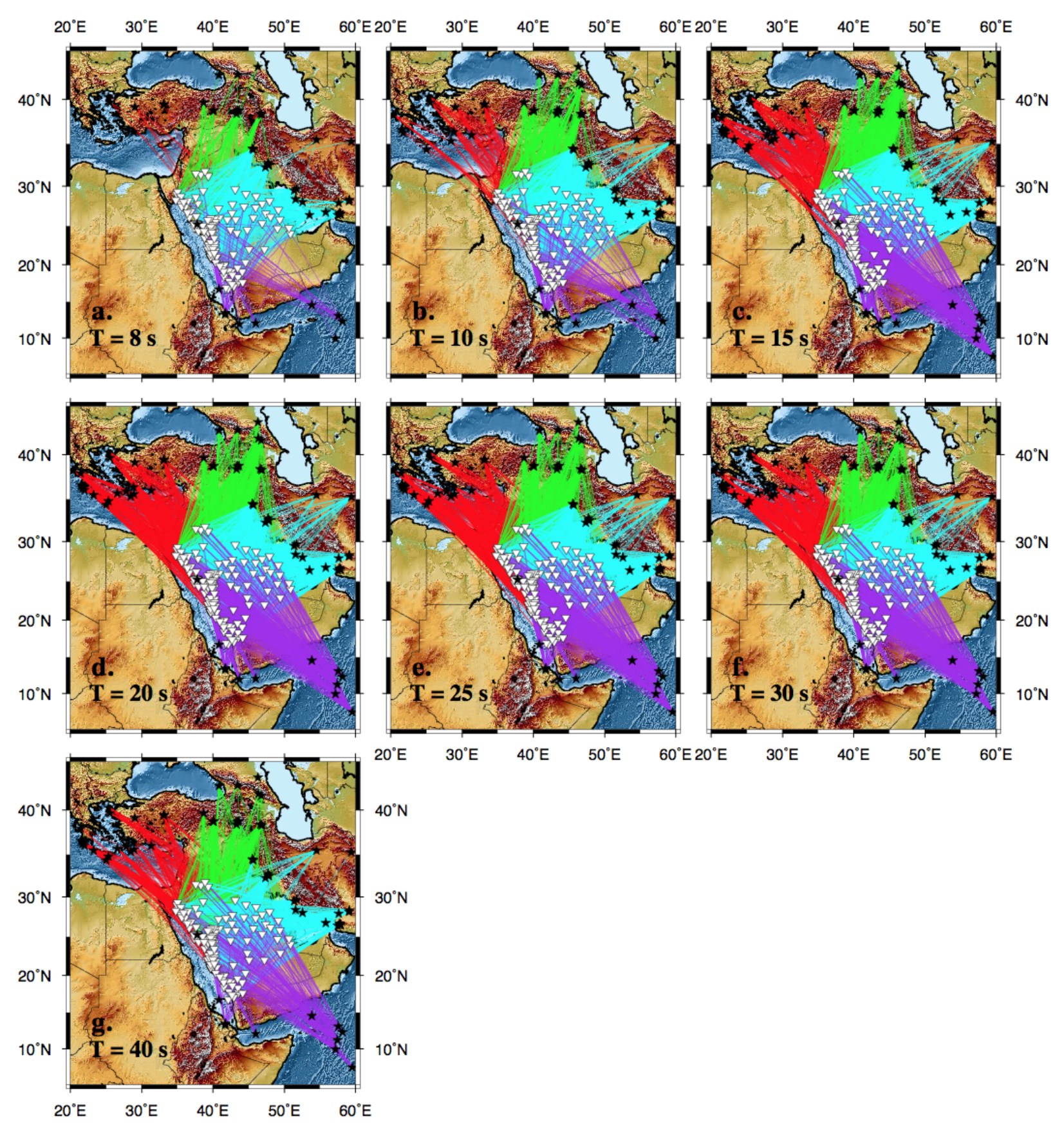

633 Figure 2. Distribution of earthquakes (black stars), stations (white triangles), and Rayleigh-wave

634 ray-paths at periods $\mathrm{T}=8-40 \mathrm{~s}$. Four ray-path clusters are indicated by different colors. Cluster

6351 (red) contains the rays from northwestern directions. Cluster 2 (green) includes the rays from

636 north-northeast. Cluster 3 (cyan) consists of the rays from the east. Cluster 4 (violet) comprises

637 the rays from south-southeast (e.g., Red Sea, Gulf of Aden and Arabian Sea). 


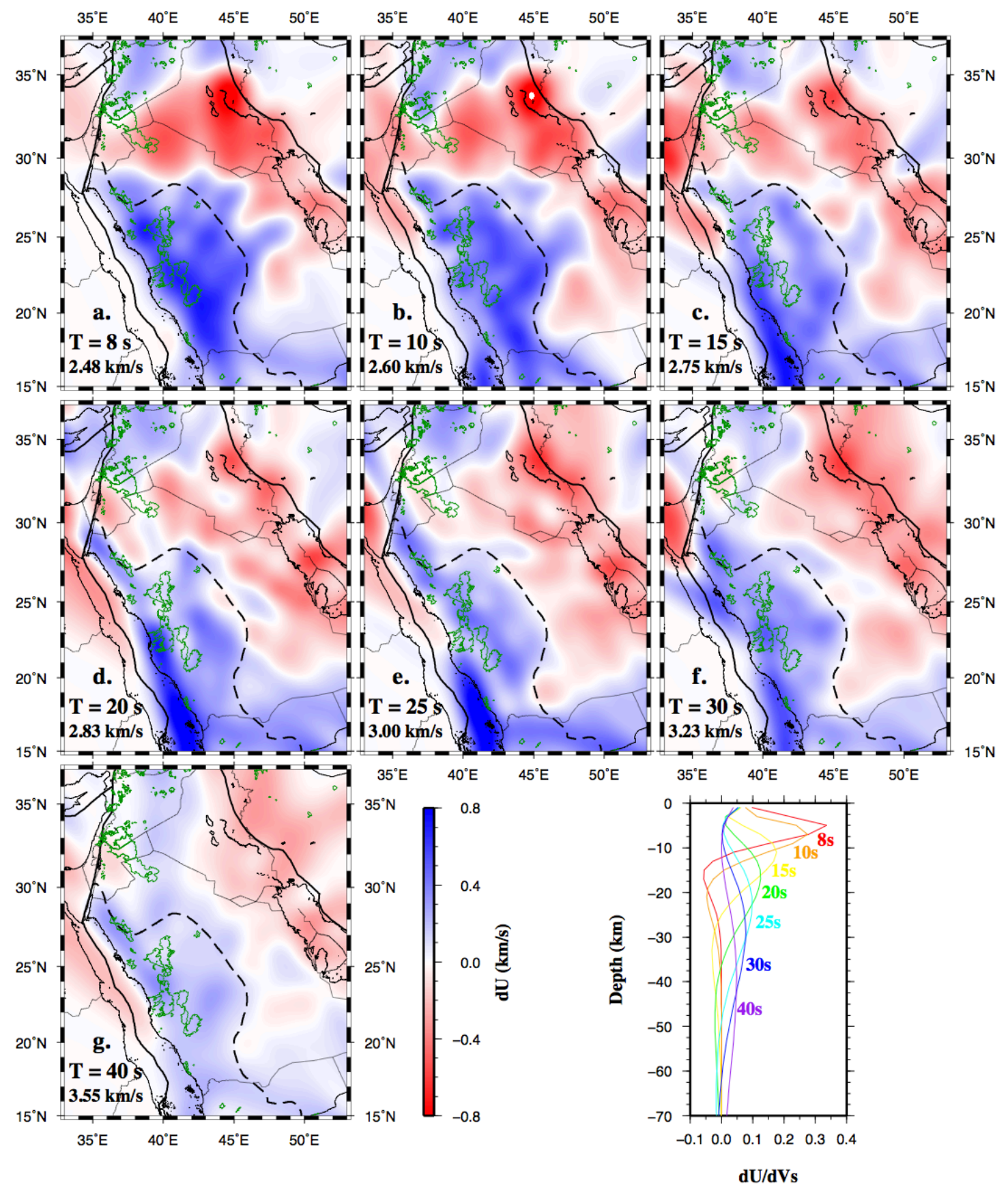

639 Figure 3. Maps of Rayleigh-wave group-velocities (periods $T=8-40 \mathrm{~s}$ ), showing perturbations

640 relative to the corresponding average group-velocities (stated in each panel). Green contours

641 outline the Cenozoic volcanism (Fig. 1). Dashed black line marks the boundary between the

642 Arabian Shield and the Arabian Platform. For reference, we also plot the shear-wave sensitivity

643 kernels of the Rayleigh-wave group-velocities at several periods. 

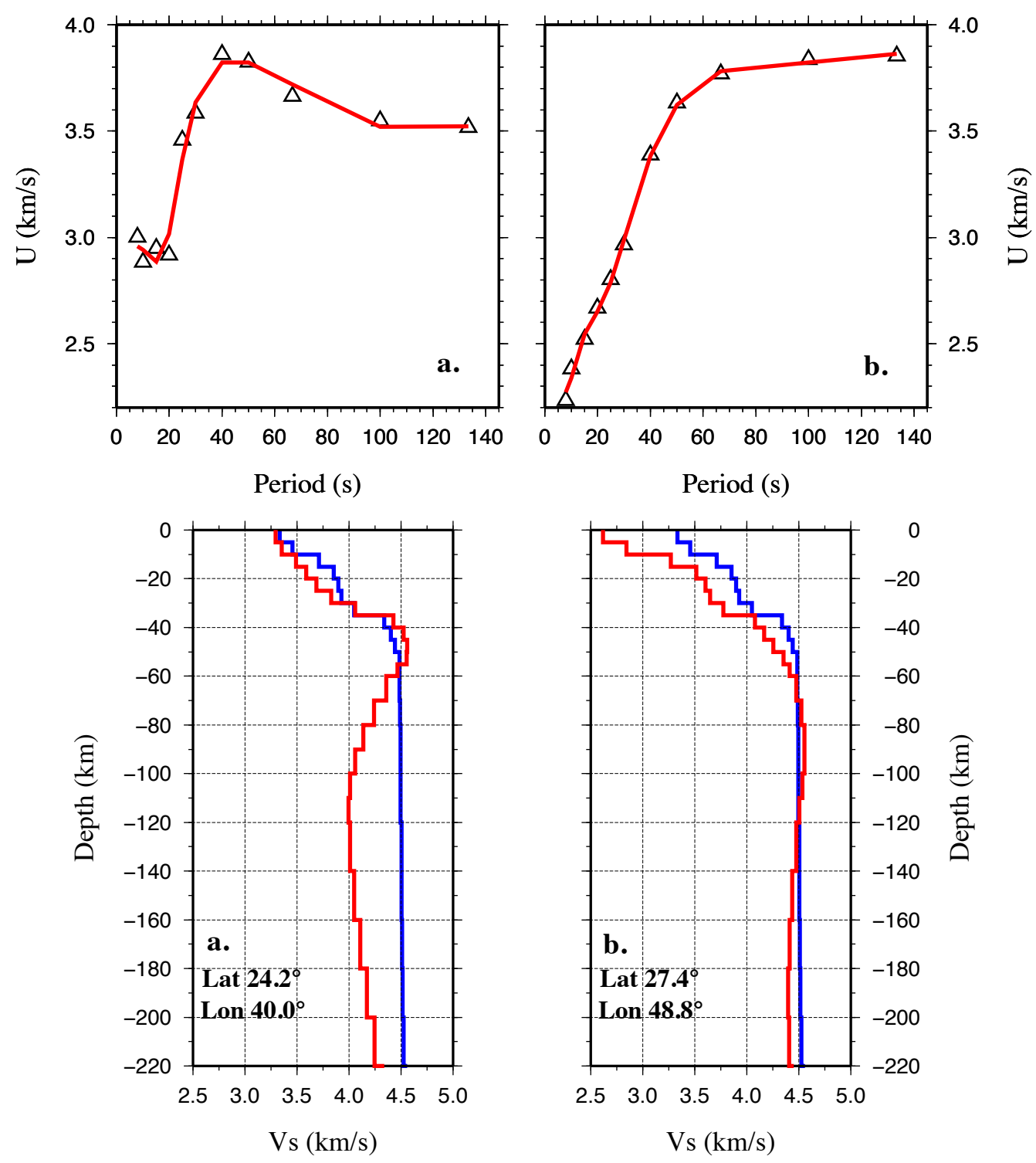

644

Figure 4. Examples of the 1-D shear-velocity inversion at two nodes - (a) $24.2^{\circ} \mathrm{N}, 40.0^{\circ} \mathrm{E}$ on the

646 Arabian Shield; (b) $27.4^{\circ} \mathrm{N}, 48.8^{\circ} \mathrm{E}$ on the Arabian Platform. The top panels show observed

647 dispersion data (triangles) extracted from our tomography results (periods $\mathrm{T}=8-40 \mathrm{~s}$ ) and from

648 Ma and Masters (2014) (periods T = 40 - 133 s), as well as the predicted dispersion curves (red).

649 The bottom panels display the starting models (blue) and the inverted 1D shear-wave velocity models (red) at each location. 

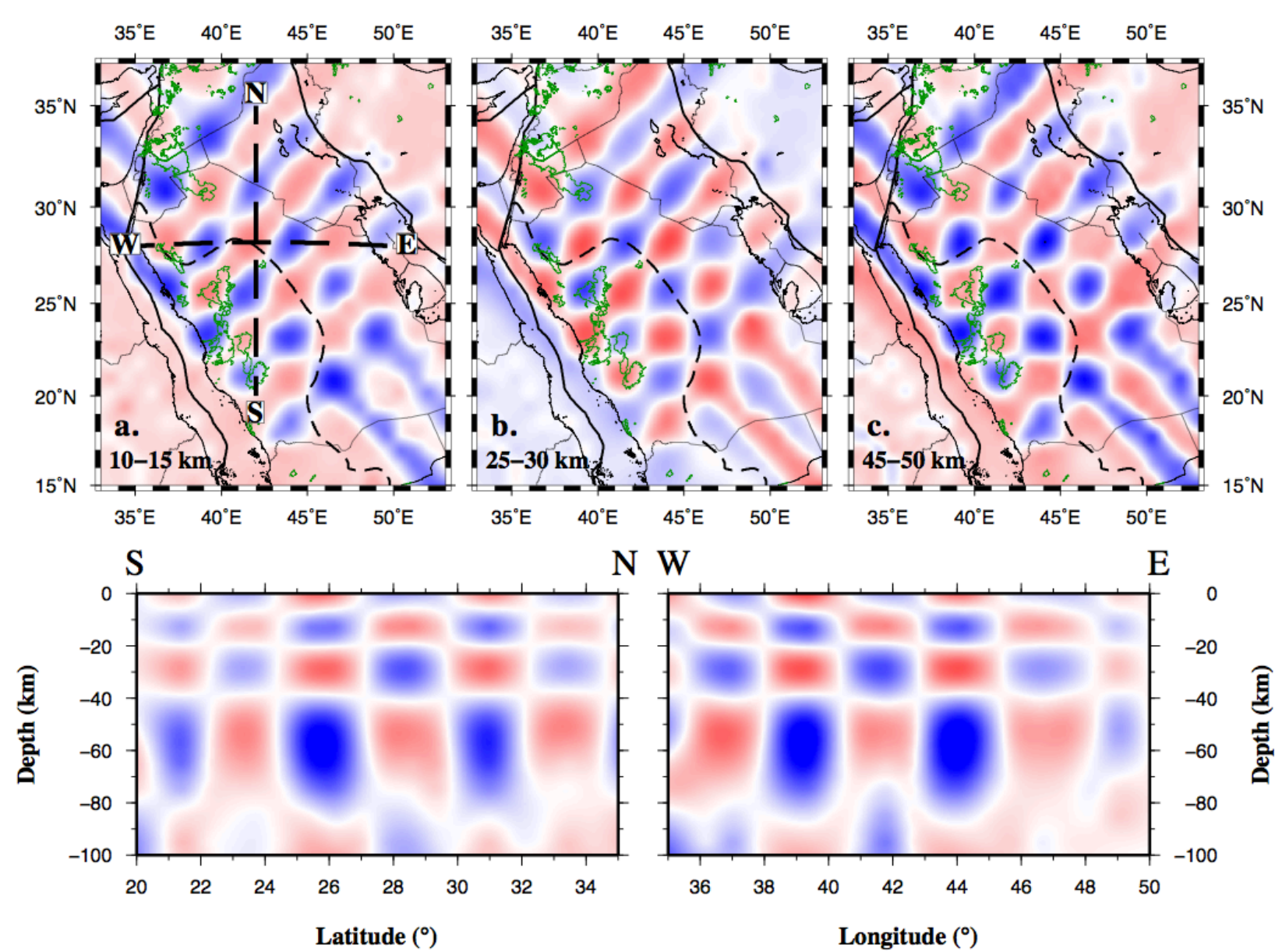

N W

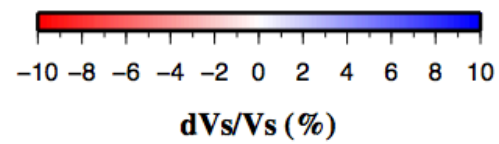

dVs/Vs (\%)

652 Figure 5. Resolution tests for our study region, applying a $2.5^{\circ} \times 2.5^{\circ}$ initial checkerboard pattern

653 with imposed anomalies of $\pm 0.4 \mathrm{~km} / \mathrm{s}$ (i.e., $\pm 10 \%$ ). The top row displays the recovered shear-

654 wave velocity patterns (at three different depths), indicating excellent resolution for the region of

655 interest of the Cenozoic volcanic fields (marked by green lines). The bottom row presents the

656 recovered depth-dependent velocity structure in two vertical cross-sections (locations in top-left

657 panel). 


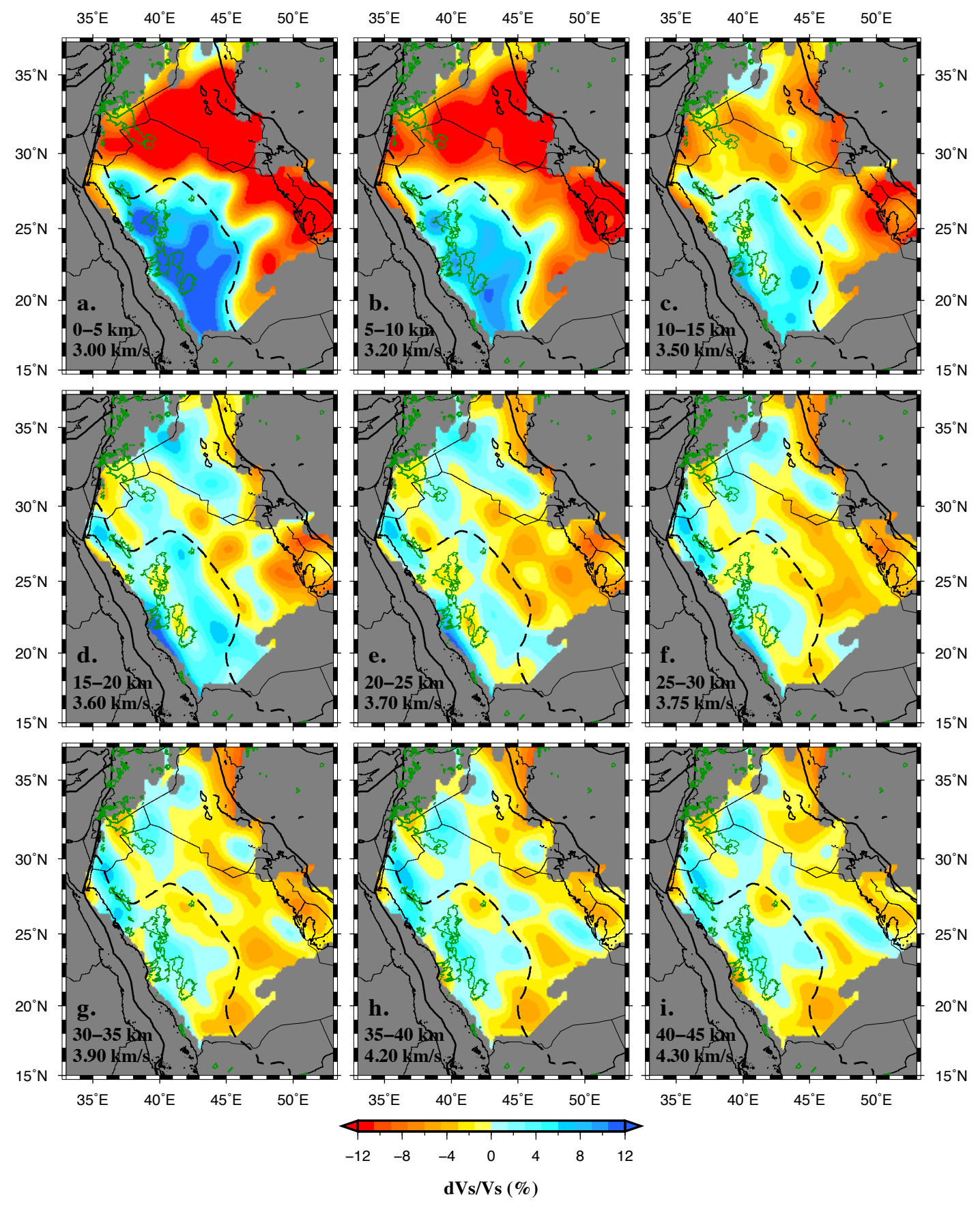

659 Figure 6. Horizontal slices of shear-velocity anomalies (in percentage deviation from the 660 reference velocities) over the crustal depth range of the Arabian Plate $(0-45 \mathrm{~km})$. The reference

661 velocity values and depths are indicated in the bottom-left corners of each panel. Green contours

662 outline the regions of Cenozoic volcanism. Dashed black line marks the boundary between the

663 Arabian Shield and the Arabian Platform. Note that we only show shear-wave variations over the 
664 region which we consider well resolved based on the ray-density maps (Fig. S1) and the 665 checkerboard resolution tests (Fig. 5, S4, S5). 


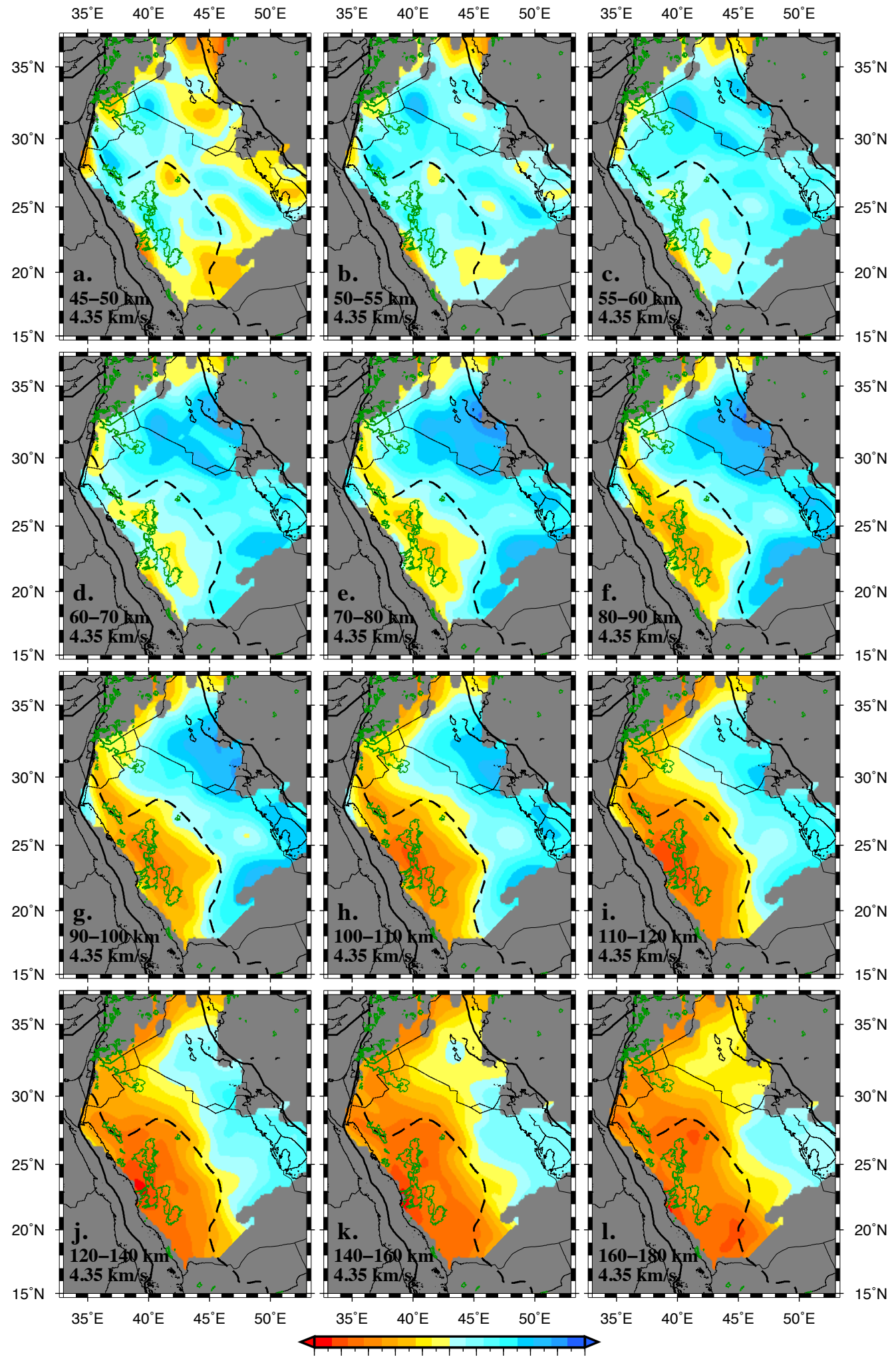

$\begin{array}{lllllllllll}-10 & -8 & -6 & -4 & -2 & 0 & 2 & 4 & 6 & 8 & 10\end{array}$ 
667 Figure 7. Same as Figure 6, but for the upper-mantle level (45 - $180 \mathrm{~km})$ beneath Saudi Arabia.

668 Here, a common reference shear-wave velocity of $4.35 \mathrm{~km} / \mathrm{s}$ is applied.
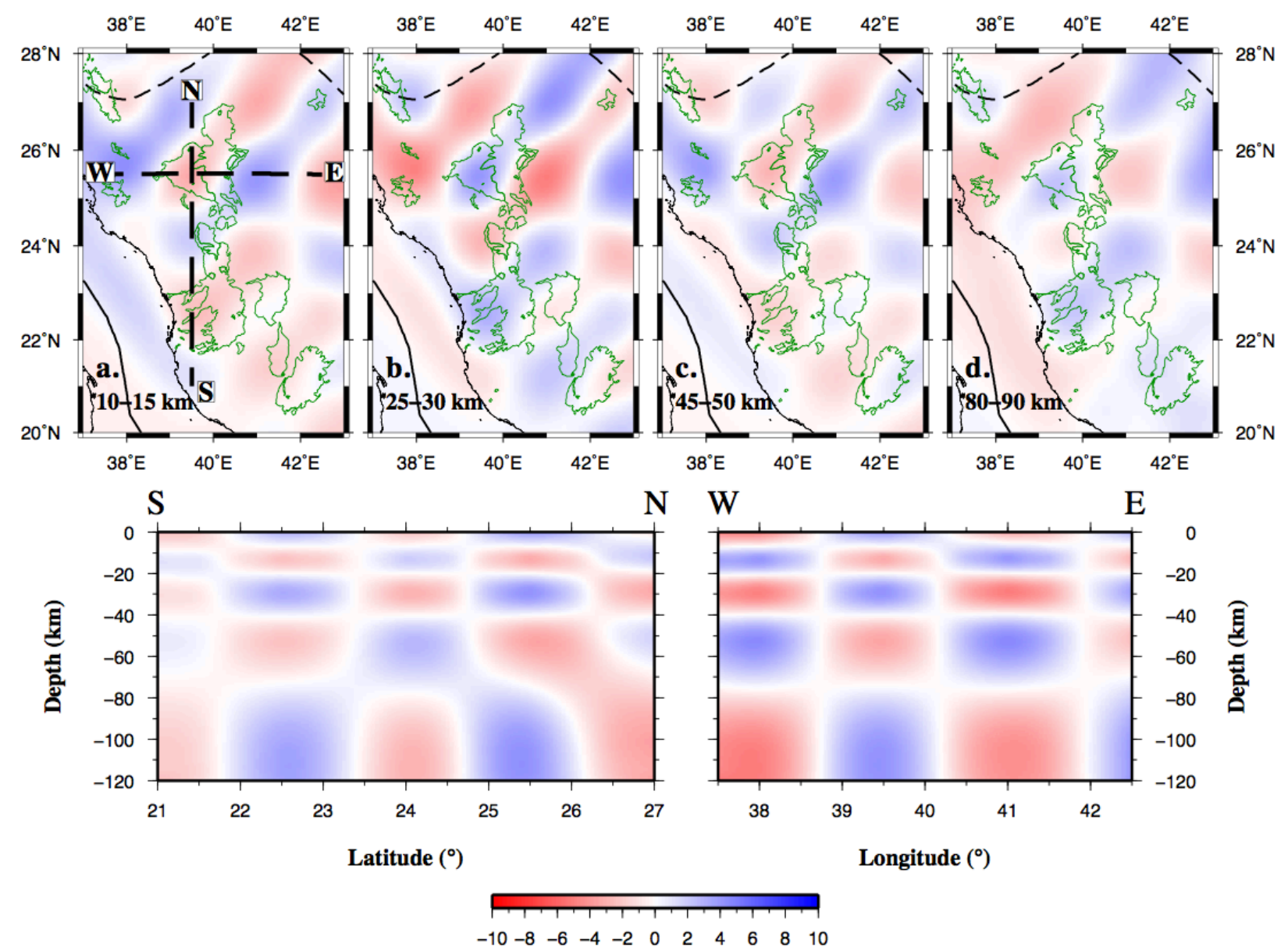

dVs/Vs (\%)

670 Figure 8. Resolution tests focusing on the regions of Cenozoic volcanism in the western Arabian

671 Shield. A $1.5^{\circ} \times 1.5^{\circ}$ checkerboard pattern with imposed S-velocity anomalies of $\pm 0.4 \mathrm{~km} / \mathrm{s}$ (i.e., $672 \pm 10 \%$ ), also varying with depths, is applied as initial test model. See Figure 5 for further details.

673 Note that the recovered model indicates adequate resolution over the volcanic areas, while 674 resolution rapidly degrades near the Red Sea. 


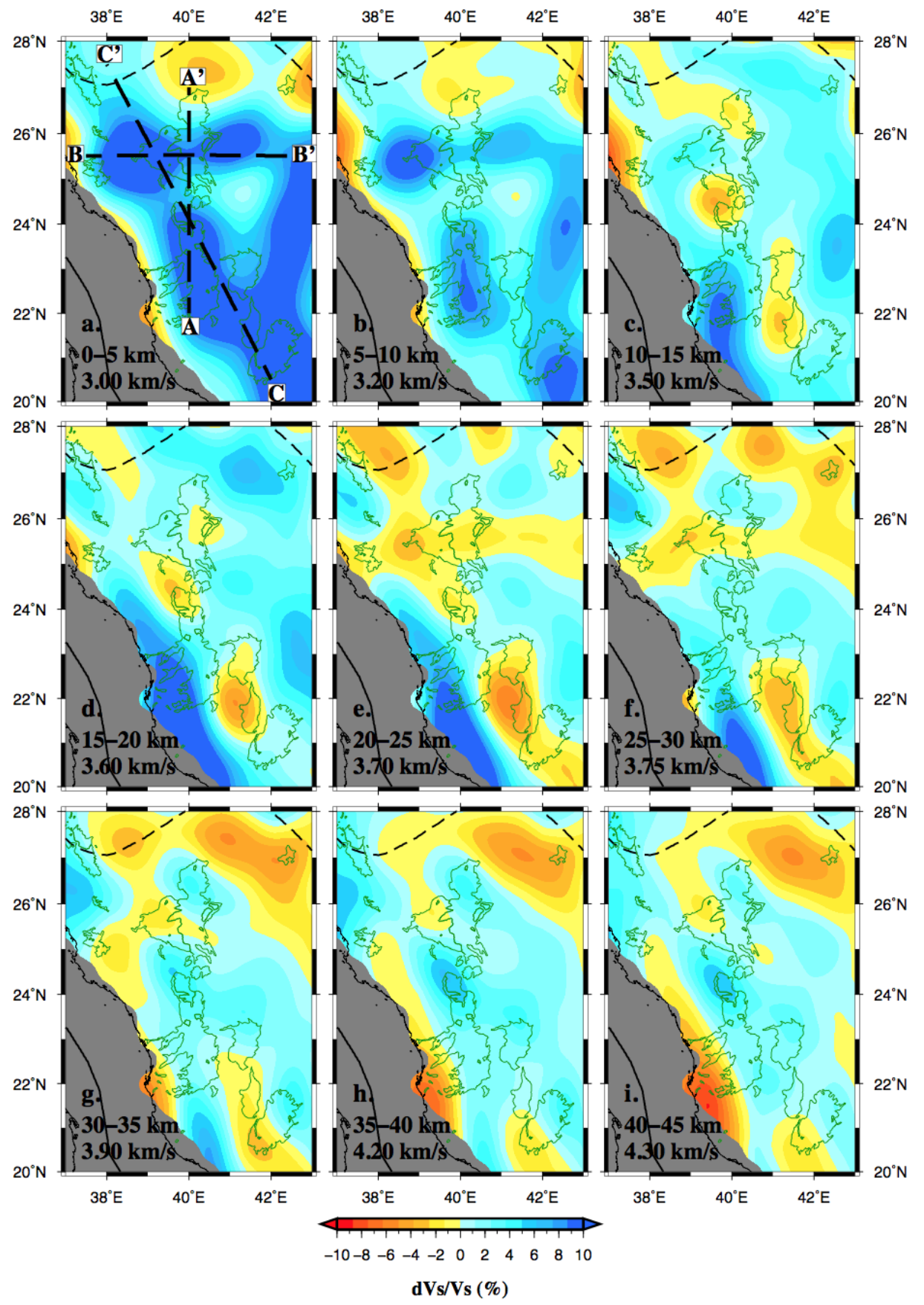

676 Figure 9. Horizontal slices of shear-velocity anomalies at the crustal levels $(0-45 \mathrm{~km})$ below the

677 Cenozoic volcanic regions, given in percentage deviation from the depth-dependent reference S-

678 wave speeds (specified in the bottom-left of each panel). Green lines mark the volcanic areas.

679 Dashed thick black lines in panel (a) indicate the three cross sections shown in Figure 10. 

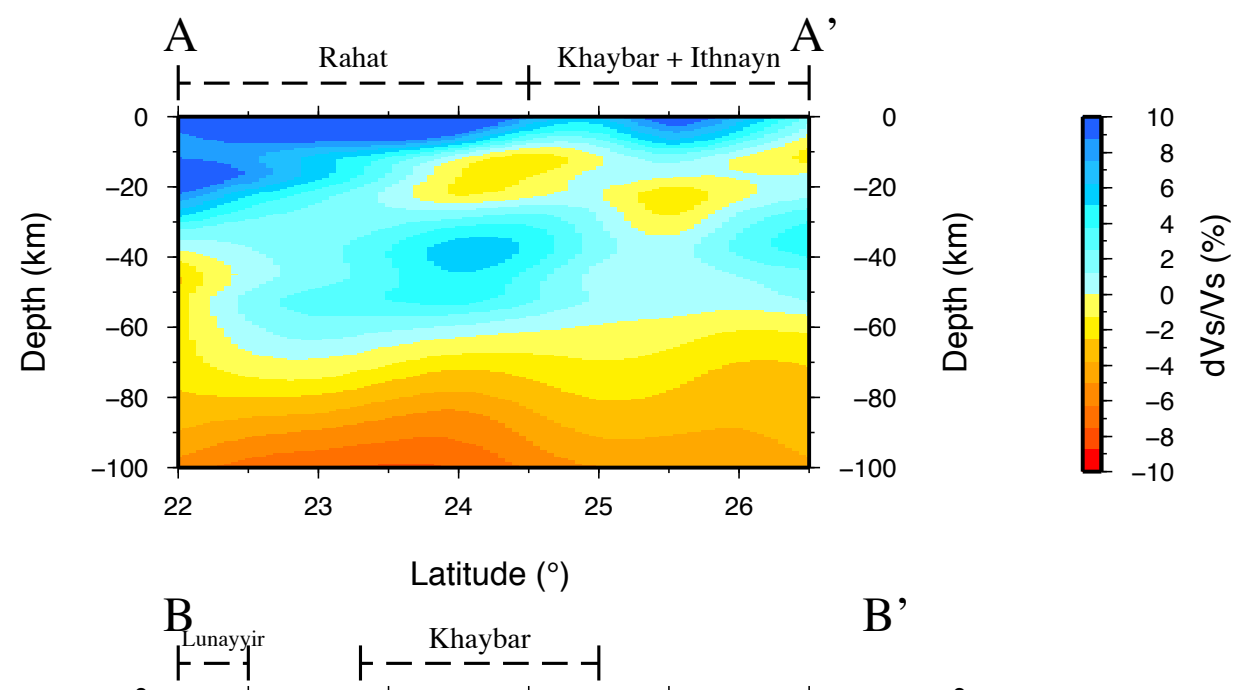

$\mathrm{B}^{\prime}$
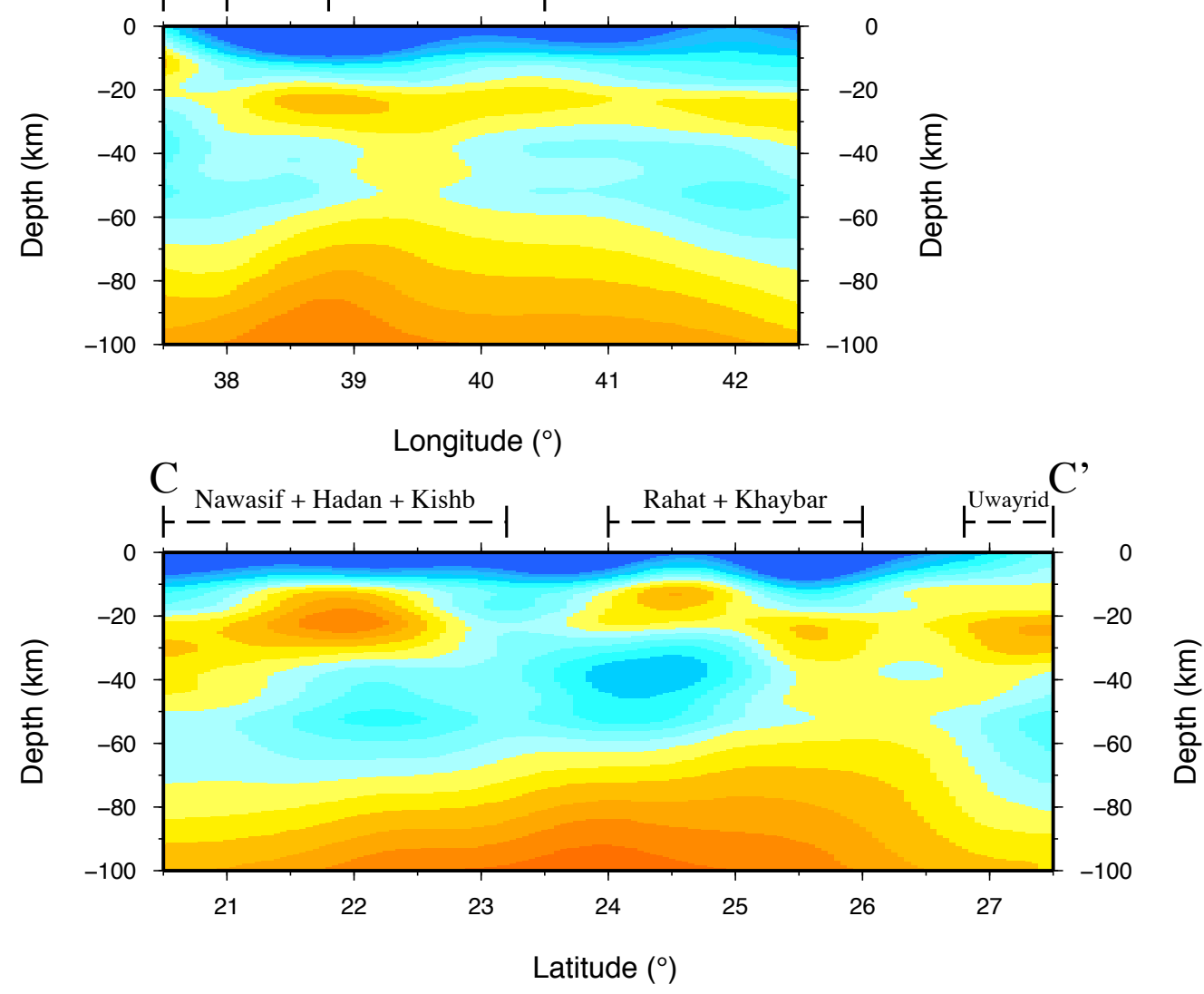

681 Figure 10. Vertical profiles of shear-velocity anomalies (in percentage deviation) for the three 682 transects shown in Figure 9a. The reference velocities for each depth-range are indicated in $683 \quad$ Figure 6 and 7. 